\title{
Impact of Health Care Sector on Indian Economic Growth and Challenges: A Socio-Legal Analysis
}

\author{
Rubi Talukdar ${ }^{1}$, Prabir Kumar Pattnaik ${ }^{2}$ \\ ${ }^{1}$ Assistant Professor, ${ }^{2}$ Professor, Siksha 'O'Anusandhan National Institute of Law, \\ Siksha 'O'Anusandhan Deemed to be University, Khandagiri, Bhubaneswar, Pin-751030, Odisha, India
}

\begin{abstract}
A large quantity of India's population is reduced to destitution because of high coverage health-care expenses and also suffering from antagonistic consequences of poor health care services. India has accomplished several gains in the field of Health since the new millennium, such as, life expectancy at birth has increased, the infant mortality and maternal mortality ratio has fell down and the spread of contagious diseases such as HIV/AIDS has been controlled etc. Again WHO, recently officially declared India free from maternal and neonatal tetanus and also polio free. But at the same time, among the five BRICS Nations, namely (Russia, Brazil, South Africa, China and India), India is considered as the poorest performer on the health indicators. India has failed to sufficiently protect its citizens against poor quality of health care as well as financial risks associated with health expenditure.

Health Care Industries of a Country can play crucial roles not only in providing quality care and improving access to medicines for the citizens, but also in developing economic growth of the Country. Again, as it is universally accepted that Health is magnificent and efficacious investment for the economic growth of a Nation, this paper will analyze several major challenges that India need to be addressed, most notably the poor and ineffective regulation of the country, the rapid growth of commercialization of health care services, inadequate public expenditure along with very low level of public expenditure. Here the approach of Judiciary towards the various challenges surrounding the health care services in India will also be discussed.
\end{abstract}

Keywords: Health, Drugs, rules \& regulations, Public Expenditure, Judicial approach

\section{Introduction}

The Union Government of India has reported numerous strategy activities, for example, The National Health Policy, 2017 (NHP, 2017) seeks to reach everyone in a comprehensive integrated way to move

\footnotetext{
Corresponding Author:

Rubi Talukdar

Assistant Professor, Siksha 'O’ Anusandhan National Institute of Law,

Siksha 'O' Anusandhan Deemed to be University, Khandagiri, Bhubaneswar, Pin-751030, Odisha, India Phone No.: 8638370278

e-mail: rubitalukdar@soa.ac.in
}

towards wellness. It aims at achieving universal health coverage and delivering quality health care services to all at affordable cost. India has recorded a few gains in human services part since the new thousand years. For instance, life expectancy at birth has ascended from 62.5 years (in 2000) to 66 years in $2013^{2}$; maternal death rate tumbled to 167 for each 100000 livebirths from 301 for every 100000 livebirths in the middle of 2001 and 2013 ${ }^{3}$; the spread of HIV/AIDs has been controlled. WHO authoritatively pronounced India polio free in 2014 and in 2015 announced India free of maternal and neonatal tetanus.

Be that as it may, then again, because of various instances of hardships in health care administrations, individuals in India are confronting challenges for example catastrophe of sterilization death (Chhattisgarh), 
incurred visual deficiency because of cataract opertion (Punjab), demise of 100 people groups from utilization of illegal alcohol (Mumbai), expanding number of dengue cases all through the nation etc. ${ }^{4,5}$ India represents $27 \%$ of all the neonatal death and $21 \%$ of all the child deaths (younger than 5 years) in the world. ${ }^{6}$ Furthermore, over $6 \%$ of ladies are seriously undernourished which is among the most astounding in low-income and middleincome countries. ${ }^{7}$ The normal age of an individual having their first heart attack is 50 years, in any event 10 years sooner than in developed countries ${ }^{8}$. Among the five BRICS Nations, to be specific (Russia, Brazil, South Africa, China and India), India is considered as the poorest performer on health indicator. ${ }^{9}$ Despite a higher salary for every head and two decades of supported monetary development, the nation has fallen behind Bangladesh and Nepal on numerous health indicators. India has neglected to sufficiently ensure its residents against money related dangers related with health care expenses and keep on driving millions into poverty. ${ }^{10}$

As Health is eminent and effective venture for the financial development of a Nation, there are a few noteworthy difficulties that India should be tended to:

Expanding expenses of medications and unreasonable utilization of innovation: The Indian Pharmaceutical retail market, dissimilar to developed markets like Europe and US, is commanded by brandedgeneric items. At the point when the market is pegged at Rs. 87000 crore every year, the vast majority of the items accessible in the market are branded items sold by the private firms. ${ }^{11}$ The Government of India spending just around $0.1 \%$ of GDP on Government supported medications. So as to enable the client to purchase a less expensive however quality item, the Jan Aushadhi Campaign was propelled by the Government in 2008. The point was to give 361 medications in their exhaustive structure at sensible procedure through Government-run-pharmacies. ${ }^{12}$ The Government additionally embraces the solution of conventional medications in the public health facilities and furthermore gives the monetary allowance to get fundamental drug that ought to be conveyed at public health facilities free of expense through the National Rural Health Mission. ${ }^{13}$ The Department of Pharmaceuticals has drafted another pharmaceutical policy in 2012, that proposes to adjust the requirement for value command over prescription. The Drugs (Prices Control) Order of 2013 tries to authorize the costs of imperative prescriptions and controlled mass medications and details to ensure their accessibility in the Country. ${ }^{14}$ However, legitimate execution of these activities has been conflicting and shifted in State to State. The arrangement to build up in excess of 600 conventional medication drug stores by 2012 , however against it just 170 drug stores had been opened in chosen States, of which 99 drug stores were workable, in October 2014. As of late, under Pradhan Mantri Jan Aushadhi Yojana (PMJAY), so as to make quality medications accessible at sensible costs to individuals, it has been chosen to open 3000 Jan Aushadhi Stores the nation over before the finish of $2017 .{ }^{15}$

Again Indian Medical Device Industry is likewise muddled. About $99 \%$ of medical devices in India are not controlled, for example, glucometers, ultrasound machines, endoscopes and ventilators and so on. Under the Medical Devices Rules, 2017, just around 20 devices, (for example, stents, orthopedic inserts, visual focal points and so forth) were covered among around 5000 sorts of medical devices in the market. ${ }^{16}$

Weak governance, accountability and ineffective regulation of the Country: The composers of the Constitution of India, referenced that among the three lists under Seventh Schedule, 'health' enrolled under the State list, with the goal that it is the prime duty of the State Governments to convey appropriate and viable health care services to the general population. Be that as it may, both the Central and State Governments need to work connected at the hip to guarantee effective health care delivery services, as right around $33 \%$ of subsidizing for medicinal services originates from the Central Government. One most significant obstruction of the wellbeing administration of our nation is that there is an insufficient combination between different offices inside the Ministry of Health further more, Family Welfare that manage wellbeing administrations, medicinal training, family welfare and different services identified with wellbeing, for example, services the individuals who manage water and sanitation. The Government of India, in the previous 6 years, presented a few new Laws and guidelines to strengthen administration of the social insurance framework in the nation, yet these laws and guidelines are not appropriately executed. For instance, the Clinical Establishment Act, 2010, which accommodates enrollment and guideline of clinical foundations and endorses least measures of offices and administrations to be given by them, has been authorized by just 9 of 29 States and the greater part of the Union Territories of India. The Mental Health Care Bill-2013 includes extraordinary measures to be embraced by 
the Government guaranteeing everybody appropriate to get to emotional wellness care and treatment from government run or supported administrations. This progressive enactment was presented in Rajya Sabha and till date sitting tight for enactment. ${ }^{17}$ Responding to a Supreme Court of India's order, The Central Government of India, in 2013, presented new principles for clinical preliminaries to affirm the security when testing new medications. Anyway the extent of these guidelines isn't clear and explicit. As of late, the amended Medical Devices Rules are required to have sweeping effect on the therapeutic devices industry as this is the primary enactment in India managing medicinal devices. For this, the players engaged with the assembling, bundling, testing, dissemination, deal and import of medicinal gadgets must need to get acquainted with the new guidelines and need to actualize the significant arrangements to their business. ${ }^{18}$

Low Public Expenditure on Health: The total expenditure on health per head in India tumbled from $4.5 \%$ of GDP in $2004-2005$ to $4.0 \%$ of GDP in 2013-2014. ${ }^{19}$ However during this equivalent period, genuine open use per head expanded by $40 \%$-a lot of this development was accomplished by 2009-10, with virtual stagnation since 2010-2011. In spite of this expansion, public health expenditure use as an extent of GDP stays low, at simply $1.28 \%$ of the Nation's GDP in 2013-2014.

Public Health Expenditure is added to by both the Central and State Governments, leaving monetarily more fragile States increasingly powerless to low general wellbeing ventures. In spite of the fact that the Twelfth Five Year plan (2012-17) had required a change in perspective and suggested the Central Plan consumption (the Central Government's help to State Governments for their yearly plans) to increment by about $34 \%$ consistently, use by the focal government has expanded by under $1 \%$ every year between 2008-09 and 2012-13. Then again, the genuine State consumption on wellbeing, for example in the wake of considering, has expanded by $7 \%$ per year. ${ }^{20} \mathrm{As}$ an outcome, the focal government's offer in general wellbeing use has stayed under $30 \%$ since 2010 and has decreased continuously. Spending discharges from the focal government are frequently said to be founded on the reserve absorptive limits of the states and in light of the fact that many state governments in India neglect to utilize dispensed assets inside the monetary year, genuine discharged spending plans are regularly a lot littler than promised. ${ }^{21}$ Although now and then outfitted as purposes behind diminishing budgetary allotments, these low absorptive limits may essentially reflect basic shortcomings in the health services framework that should be tended to with more resources and an alternate way to deal with arrangement and delivery of care. ${ }^{22}$

India's current foundation is sufficiently not to take into account the developing interest. While the private segment rules human services conveyance the nation over, a greater part of the populace living beneath the destitution line are dismissed in some way or another. They can spend Rs 47 every day in urban zones, Rs 32 every day in provincial territories and these individuals keep on depending on the less financed and less staffed open area for its human services needs, because of which their medicinal services needs remain neglected. Additionally, most of medicinal services experts happen to be focused around urban territories where purchasers have higher paying force, leaving country regions underserved, as the table beneath uncovers. India clings to the world normal in number of doctors, still $74 \%$ of India's specialists take into account $33 \%$ of the urban populace, or close to 440 million individuals inside a nation with populace of in excess of a billion. ${ }^{23}$

Judicial Approach towards 'Health care' in India: Health is regularly considered as a scientific discipline that requires ability, information and expertise of medication limited to the medicinal experts and researchers however it incorporates financial and political determinants just as characterized by the WHO. Right to health has been regularly constrained to right to health care that has frequently kept to the evenhanded access and accessibility of health care services.

The Supreme Court in Paschim Banga Khet Mazdoor Samithy and Ors. V. Province of West Bengal and Anrs., while augmenting the extent of Article 21 and the administration's obligation to give medicinal guide to each individual in the nation, held that in a welfare express, the essential obligation of the legislature is to verify the welfare of the general population. Giving sufficient therapeutic offices to the general population is a commitment embraced by the administration in a welfare state. The administration releases this commitment by giving restorative consideration to the people trying to benefit of those offices. Article 21 forces a commitment on the State to protect the privilege to life of each individual. Conservation of human life is therefore, of central significance. The administration emergency clinics kept running by the State are will undoubtedly 
broaden restorative help for safeguarding human life. Disappointment with respect to an administration emergency clinic to give auspicious medicinal treatment to an individual needing such treatment, results infringing upon his right to life ensured under Article 21.

In State of Punjab v. Slam Lubhaya Bagga, [(1988) 4 se c 117] Hence, the right of a citizen to live under Article 21 throws on commitment on the State. So it is for the State to tie down health to its resident under Article 47. The Court additionally held that the State can neither inclination nor state that it has no commitment to give medicinal facilities. In the event that that were so it would be the infringement of Article 21. No State or nation can have boundless assets to spend on any of its undertakings. That is the reason it just favors extends that seem attainable. Similar remains constant for giving medical facilities to its residents. Arrangement of facilities can't be boundless. It must be to the degree that funds license. In the event that no scale or rate is fixed, at that point on the off chance that private centers or medical clinics increment their rate to extreme scales, the state would be undoubtedly repay the equivalent. The guideline of fixing of rate and scale under such an approach is legitimized and can't be held to damage Article 21 or Article 47 of the Constitution.

\section{Conclusion}

India is a land loaded with open doors for players in the medical device industry. India's health care services industry is one of the quickest developing parts and in the coming 10 years it is relied upon to reach $\$ 275$ billion. The nation has likewise turned out to be one of the main goals for top of the line demonstrative administrations with colossal capital venture for cutting edge indicative offices, in this way obliging a more noteworthy extent of populace. In addition, Indian health care consumers have turned out to be increasingly cognizant towards their health care services upkeep. Indian medical services area is tremendously enhanced and is loaded with circumstances in each section which incorporates suppliers, payers and therapeutic innovation. With the expansion in the challenge, organizations are hoping to investigate for the most recent elements and patterns which will have positive effect on their business. ${ }^{24}$

The Central government ought to contribute towards reinforcing the state health care framework system, give specialized help and money related impetuses, specifically to failing to meet expectations states and boost conspires that are adaptable in their application to oblige the extraordinary varieties between states. In the meantime, the states must take advantage of the expanded portion of expense incomes and work towards expanding the general wellbeing consumption. Networks must be effectively enabled to connect with this extreme vision of medicinal services. Conveying on its guarantee of guaranteeing a healthy India ought to be the highest need of the Indian Government. We trust that, when India achieves the achievement of 75 years of autonomy in 2022, no Indian ought to must be denied their fundamental right to great quality health care services because of lack of administrations or facilities and no Indian should confront impoverishment because of health care.

\section{Conflict of Interest: Nill}

\section{Source of Funding: Self}

Ethical Clearance: NA

\section{Reference}

1. Ministry of health and family welfare. National Health Policy 2017. Available at https://www.nhp. gov.in/nhpfiles/national_health_policy_2017.pdf

2. WHO Global Health Observatory Indicator View. Life expectancy (Women and Health) Data. Available at http://apps.who.int/gho/data/node.imr. WHOSIS_000001?lang=en

3. Register General of India, Maternal Mortality ratio bulletin 2011-13. New Delhi: Office of Registrar General, 2015.

4. Bagcchi S. Medical Negligence and Substandard drugs caused death in Indian Sterilization Programme.BMJ. 2015 Sep 8;351

5. Bagcchi S. Dengue Surveillance poor in India. Lancet 2015;386(10000):1228

6. Liu L, Oza S, Hogan D, et al. Global, regional and national causes of child mortality in 2000-13, with projections to inform post-2015 priorities: an updated systematic analysis. Lancet 2015; 385: 430-40.

7. Razak F, Corsi DJ, Slutsky AS, et al. Prevalence of body mass index lowers than 16 among women in low- and middle-income countries. JAMA 2015; 314: $2164-71$.

8. Patel V, Chatterji S, Chisholm D, et al. Chronic diseases and injuries in India. Lancet 2011; 377: 
413-28.

9. Marten R, McIntyre D, Travassos C, et al. An assessment of progress towards universal health coverage in Brazil, Russia, India, China and South Africa (BRICS). Lancet 2014; 384: 2164-71.

10. Van Doorslaer E, O'Donnell O, Rannan-Eliya RP, et al. Effect of payments for health care on poverty estimates in 11 countries in Asia: an analysis of household survey data. Lancet 2006; 368: 1357-64.

11. Sushmi Dey. Jan Aushadhi: Government's low cost generic drugs from July 1. The Times of India.2015. Available at at https://timesofindia.indiatimes. com/india/Jan-Aushadhi-Governments-low-costgeneric-drugs-from-July-1/articleshow/46101725. $\mathrm{cms}$

12. Department of Pharmaceuticals. Jan Aushadhi Scheme-A new business plan. New Delhi, India: Ministry of Chemicals and Fertilisers, Government of India, 2013.

13. Ministry of Health and Family Welfare, Government of India. Generic drugs. Press Information Bureau. July 18, 2014. New Delhi: Ministry of Health and Family Welfare.

14. The Gazette of India. National Pharmaceutical Pricing Policy Notification. New Delhi, India: Government of India, 2012.

15. Press Information Bureau, Government of India. 3000 Jan Aushadhi Stores to be opened.2016 August. Available at http://pib.nic.in/newsite/ printrelease.aspx?relid $=148168$

16. Paliwal A. Why imminent Indian government regulations on medical devices have everyone worried.Scroll in. 2017 Jan 16. Available athttps:// scroll.in/pulse/826606/why-imminent-indiangovernment-regulations-on-medical-devices-haveeveryone-worried

17. Choudhary LN and Shekhar S. The Mental Health Care Bill 2013: A Critical Appraisal.Indian J Psychol Med. 2015 Apr-Jun; 37(2): 215-219.

18. Pandey A. Implications of the Medical Devices Rules, 2017 on Industry Practices.ipleaders.2017. Available at https://blog.ipleaders.in/medicaldevices-rules/

19. WHO. WHO Global health expenditure database NHA indicators. 2014. Available at http://apps. who.int/nha/database/ViewData/Indicators/en

20. Mukhopadhyay I. The Hindu Business Line, June
$26,2015$.

21. Mukhopadhyay I. Fund $\mathrm{fl}$ ow and utilisation bottlenecks under NRHM: a study of Uttar Pradesh and Chhattisgarh. In: Khan MU, Sigamani P, eds. Strategic public health management: lessons for emerging economy. New Delhi: Blooms Berry, 2013.

22. Planning Commission of India. High Level Expert Group Report on universal health coverage for India. New Delhi, India: Government of India, 2011.

23. KPMG Report on Health Care Access Initiatives, August 2016 by KPMG, India

24. Department of Industrial Policy and Promotion (DIPP), RNCOS Reports, Media Reports, Press Information Bureau (PIB), Union Budget 2017-18 